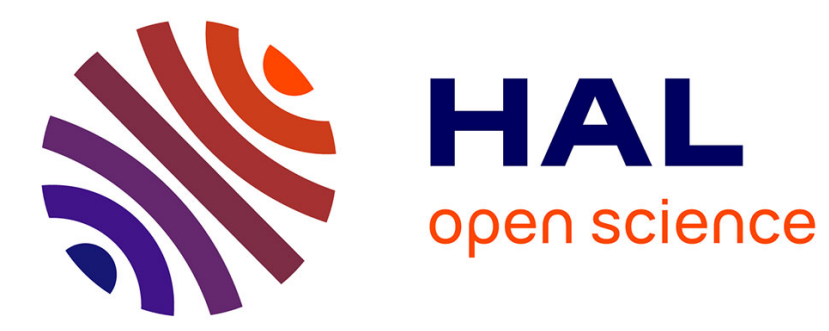

\title{
The real-time stop-skipping in the urban transportation networks
}

\author{
Khoat Nguyen Duc, Bernard Descotes-Genon
}

\section{To cite this version:}

Khoat Nguyen Duc, Bernard Descotes-Genon. The real-time stop-skipping in the urban transportation networks. MCPL 2007 - 4th IFAC Conference on Management and Control of Production and Logistics, Sep 2007, Sibui, Romania. hal-00158125

\section{HAL Id: hal-00158125 \\ https://hal.science/hal-00158125}

Submitted on 28 Sep 2007

HAL is a multi-disciplinary open access archive for the deposit and dissemination of scientific research documents, whether they are published or not. The documents may come from teaching and research institutions in France or abroad, or from public or private research centers.
L'archive ouverte pluridisciplinaire HAL, est destinée au dépôt et à la diffusion de documents scientifiques de niveau recherche, publiés ou non, émanant des établissements d'enseignement et de recherche français ou étrangers, des laboratoires publics ou privés. 


\title{
THE REAL-TIME STOP-SKIPPING IN THE URBAN TRANSPORTATION NETWORKS
}

\author{
Nguyen-Duc Khoat, Descotes-Genon Bernard
}

Gipsa-Lab - ENSIEG - INPG,

BP 46 - 38402 Saint-Martin d'Hères, France.

Email: khoat.nquyen-duc@inpq.fr, bernard.descotes-qenon@inpq.fr

\begin{abstract}
In this paper, we consider a real time regulation of traffic within disturbed transportation network. We aim to find a new schedule of bus transit system after the detection of a disturbance at a given time. Therefore, a mathematical model for a stopskipping control strategy is developed. Particularly, this model uses real-time information of locations of buses on a route and assumptions of random distribution of passenger boarding and alighting. The main objective is to minimize waiting time of passengers at stations in case of a limited bus capacity. An approach of simulated annealing algorithm is used to solve this model. Copyright (C) 2007 IFAC
\end{abstract}

Keywords: Real time rescheduling, Simulated Annealing Algorithms, Urban transportation network, Stop-Skipping strategy, Nonlinear optimization.

\section{INTRODUCTION}

In public transport system, providing a reliable service is the main objective of operation managers. Timetables, minimum passengers' waiting times and short travel time are some examples of reliable services. The great difficulty of the traffic management on public transport system is associated with the respect of the planned arrival and departure time of the buses at different stations in the network. In fact, many disturbances can occur, affect the planned arrival and departure time, and then influence the passengers' waiting time, the transit operations, and the duration of different trips on the buses. Therefore, to reduce effects of disturbances, initial schedules have to be adapted with real time conditions of the traffic. This adaptation is in fact called a real time control strategy.

The real time control strategies are designed to enhance the ability of a system in solving a specific problem when it occurs (Borne et al., 2003).

These strategies could be divided into two categories:

\footnotetext{
- Station control;

- Deadheading and adding reserve bus.
}

The first category, station control, includes delaying strategies (holding strategies), and stop-skipping strategies. These strategies are the most popular and frequently used by public transit operators to reduce passengers' waiting time.

Holding strategies are used to delay bus movement, when a bus is ahead of the schedule. Holding strategies could reduce the headway variance and the average waiting time of passengers, but also increase in-bus time of passengers and bus travel time.

Stop-skipping strategies reduce the travel time of the bus of interest. This would reduce the waiting time for passenger in-bus. However, this might increase the waiting time for passengers at skipped station and those who are requested by the driver to alight at a given station to wait for the next bus in service.

The second category includes deadheading and adding reserve buses.

A deadheading bus is a bus that usually depart empty from a dispatching terminal point to a designated station, skipping stations between the dispatching terminal point and the designated station.

This strategy could reduce both passengers' waiting time at the station beyond skipped ones, and the headway irregularity in the network. 
Adding reserve buses are useful when there are unexpected interruptions in the networks (traffic jam, accident ...). Adding reserve buses to a service can reduce passengers' waiting time, and prevent headway irregularity in the network, but it might inflict additional costs on Transport Company.

Among the strategies surveyed above, stop-skipping strategy is the focus of this paper for rescheduling problem. In this paper, stop-skipping strategy use a mathematical programming models with skipping stations as decision variables and passengers' waiting time as the objective function to be minimized.

In ( $\mathrm{Li}$ et al., 1991), the authors formulated the stopskipping problem as a nonlinear $0-1$ stochastic programming model to solve the real time scheduling, with the objective function including a minimization of both the schedule deviation on the route and the unsatisfied passenger demand.

(Eberlein et al., 1995) presented formulation for the stop-skipping problem as a nonlinear integerprogramming model to decide which bus to skip at which stations. In this model, the decision is to determine the starting and ending stations of the segment to be skipped.

(Fu and Lui., 2003) described a new dynamic scheduling strategy that aims to optimally balance the benefits of an operator and passengers. In this study, stop-skipping problem is again formulated as a non-linear integer programming, similar to that defined by (Li et al., 1991).

The formulation of (Eberlein, et al., 1995; Fu and Lui, 2003; Li, et al., 1991) all formulated the real time stop skipping as a decision during bus departure from the depot and the solution was based on very simplified heuristic algorithms. In those studies, as soon as the bus is departed from the depot, the prescribed skipping stations cannot be changed. In this sense, the application of stop skipping is not a real time. Moreover, the method in these studies cannot be implemented to respond to a bus in case of disturbances, since stop skipping can only be decided while the buses are being departed from the depot. This paper differs from the previous papers by implementing the stop skipping strategy in real-time. By this way, the strategy can be applied in more general situations and can adjusting a number and locations of skipping stations in case of disturbances and bus-limited capacity.

The mathematical model is presented in this paper contain some real conditions in the bus operation. The objective of this model is to minimize the waiting time of non-transferring and transferring passengers at any stations when disturbances occurred in the network. The remainder of this paper is organized as follows. Section 2 describes the problem statement. Section 3 presents the mathematical model. A Simulated annealing approach used to solve this model is presented in section 4. Section 5 shows an example and some results. Section 6 is for the conclusion.

\section{PROBLEM STATEMENT}

The problem considered herein investigates a strategy that could be applied for rescheduling an operation of $B$ buses on a specified line with $S$ stations.

It is assumed that at a given time, disturbances occur in the network and affect buses at the stations of a certain line. Consequently, theoretical schedules cannot be followed exactly, that compels trips to start late and causes passenger to wait longer. Therefore, to reduce effects of the disturbances, the theoretical schedules have to be adapted to real traffic conditions through rescheduling tasks. As a result, it reduces the waiting time of passengers by under taking operational decisions, such as holding, skipping...

Presently, it is a regulator, who performs these real time tasks and controls the urban network traffic by treating a real time passenger information system and automatic bus location system. This information includes:

- Departure time of buses from the last passed station;

- Capacity of buses departing their last passed station;

- Bus running times between stations

However, there is some information that will not be known such as:

- Passenger arrival rate;

- Fraction of passenger on board of buses, and alighting at stations

\subsection{Data Requirements}

In this paper, it is assumed that the following information is either available or could be estimated:

- Actual departure time of buses from the most recently passed stations;

- Bus running times between stations;

- Passenger arrival rate and alighting fractions at each station;

- Passenger service time for boarding and alighting ;

- Bus clearance time

In terms of the stop skipping strategy, the following assumptions are made:

- While considering a bus for stop skipping, the following buses will not be enabled for any control strategy;

- Once the skipping stations have been decided, the control bus drops off the passengers who are destined for stations on the skipping stations at the last station before the skipping segment;

- Skipping segment is not included transfers stations.

\subsection{Notation}

The following notation is used in the proposed formulation: 
$B \quad$ Set of buses in the network

$N \quad$ Set of lines in the network

$S \quad$ Set of stations in the network

$T \quad$ Maximum transfer time

$C_{\max } \quad$ Capacity of bus

$C_{i j}^{l} \quad$ Load of bus $l$ departing the station $i$ of line $j$

$D_{i j}^{l} \quad$ Number of passenger demand for bus $l$ at the station $i$ of line $j$

$t a_{i j}^{l} \quad$ Arrival time of bus $l$ at the station $i$ of line $j$

$t d_{i j}^{l} \quad$ Departure time of bus $l$ at the station $i$ of line $j$

$h_{i j} \quad$ Headway of the line $j$ at the station $i$

$\mu_{i j}^{l}(t) \quad$ Passenger arrival pattern at the station $i$ for bus $l$ of line $j$

$C_{i j k}^{l m} \quad$ Number of passengers transfer pattern from bus $l$ of line $j$ to bus $m$ of line $k$ at station $i$

$n r t_{i j}^{l} \quad$ Number of passengers left behind by bus $l$ at the station $i$ of line $j$

ndes $_{i j}^{l} \quad$ Passenger alighting at the station $i$ for bus $l$ of line $j$

$\varsigma_{i j}^{l} \quad$ Passenger alighting fraction at the station $i$ for bus $l$ of line $j$

$\theta_{i j}^{l} \quad$ Passenger in-bus fraction on the skipped segment

$\xi_{i j}^{l} \quad$ Decision variable, which is one if bus $l$ stops at station $i$; zero otherwise

$y_{i j k}^{l m} \quad$ Transfer variable, which is one if a transfer from bus $l$ of line $j$ to bus $m$ of line $k$ at station $i$ is possible and optimal; zero otherwise

$\tau_{a} \quad$ Alighting passenger service time $(s / p)$

$\tau_{b} \quad$ Boarding passenger service time $(s / p)$

$\alpha_{i j}^{l} \quad$ Bus clearance time

\section{MATHEMATICAL MODEL}

\subsection{Objective Function}

The objective function is sum of the waiting time of non-transferring and transferring passengers at any stations. If bus $l$ is full (overloaded bus $C_{i j}^{l}=C_{\max }$ ) when departing from station $i$, then there is an additional waiting time for passengers who could not board that bus. These passengers are assumed to wait $n r t_{i j}^{l}\left(t d_{i j}^{l+1}-t d_{i j}^{l}\right)$ minutes for the next bus. The total waiting time of non-transferring and transferring passengers is then calculated as

$$
\begin{aligned}
& \sum_{i}^{S} \sum_{j}^{N} \sum_{l}^{B}\left(\int_{0}^{t d_{i j}^{l}-t d_{i j}^{-1}} \mu_{i}^{l}(t)\left(t d_{i j}^{l}-t d_{i j}^{l-1}-t\right) d t+n r t_{i, j}^{l-1}\left(t d_{i, j}^{l+1}-t d_{i, j}^{l}\right)\right) \\
& +\sum_{i}^{S} \sum_{j}^{N} \sum_{k \neq j}^{N} \sum_{l}^{B} \sum_{m}^{B} y_{i j k}^{l m} C_{i j k}^{l m}\left(t d_{i k}^{m}-t a_{i j}^{l}\right)
\end{aligned}
$$

The first term in the objective function computes the total waiting time for all passengers who arrive randomly at their stations since the last bus departing from that station and the additional waiting time for those who are left behind at station $i$ because of an overloaded bus or of stop-skipping strategy. The second term computes the total transfer time for all transfer passengers.

\subsection{Capacity Constraint Function}

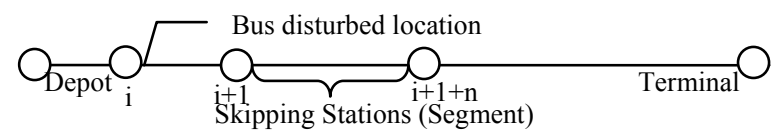

Fig.1. Route segment

In fact, the number of passengers who wait at a station can exceed the bus capacity $C_{\max }$. If the number of passengers alighting at station $i$ :

$$
\operatorname{ndes}_{i j}^{l}=s_{i j}^{l} C_{i j}^{l}
$$

At any point of time, a bus in service could be in one of the three following possible states: moving between stations, stop at station for passenger alighting and boarding, or waiting at the depot. It is assumed that when disturbance occurred and the stop skipping strategy is made, the bus disturbed is at the location immediately downstream of station $i$ and upstream of station $i+1$. If a segment $[i+1, i+1+n]$ is the skipping stations, at initiation $i+1$, among the passengers in-bus when bus disturbed arrive at station $i+1$, those who wanted to go to the station to be skipped must alight (Fig.1.). In addition, passengers on the skipping stations will have to wait for a next bus in service. The number of passenger who cannot board busl, who are requested by the driver to alight and waiting for bus $l+1$ is calculated:

$$
\begin{aligned}
& n r_{i j}^{l}=\xi_{i+1 j}^{l} C_{i-1 j}^{l}\left(1-\varsigma_{i j}^{l}\right)\left(1-\theta_{i+1 j}^{l}\right) \\
& \left.+\mu_{i j}^{l}\left(t d_{i j}^{l}-t d_{i j}^{l-1}\right)+n r r_{i j}^{l-1}\right)\left(1-\xi_{i+1 j}^{l} \theta_{i+1 j}^{l}\right)
\end{aligned}
$$

In (3) bus $l$ stops at station $i$ :

$$
\xi_{i j}^{l}=0 ; \theta_{i l}^{l}=1
$$

At station $i+1$ :

$$
\begin{aligned}
& \xi_{i j}^{l}=1 \\
& 0 \leq \theta_{i l}^{l}<1 \\
& \theta_{i j}^{l}=\prod_{i+1}^{n}\left(1-\varsigma_{i j}^{l}\right)
\end{aligned}
$$

Hence, the capacity of bus $l$ departing station $i$ of line $j$ is calculated: 


$$
C_{i j}=\mid \begin{aligned}
& C_{\max } \\
& \left(C_{i-1 j}\left(1-\zeta_{i j}^{l}\right)+\mu_{i j}\left(t d_{i j}^{l}-t d_{i j}^{l-1}\right)+n r t_{i j}^{-1}\right)
\end{aligned}
$$

\subsection{Formulation}

The objective of this model is to reduce the effect of disturbance on passengers' waiting time and transfer time in bus transit network. The question this paper attempts to answer is which station has to be skipped in order to minimize the total waiting times. Then the mathematical programming problem could be presented as follows:

Minimize

$$
\begin{aligned}
& \sum_{i}^{S} \sum_{j}^{N} \sum_{l}^{B}\left(\int_{0}^{t d_{i j}^{l}-t d_{i j}^{-1}} \mu_{i}^{l}(t)\left(t d_{i j}^{l}-t d_{i j}^{l-1}-t\right) d t+n r t_{i, j}^{l-1}\left(t d_{i, j}^{l+1}-t d_{i, j}^{l}\right)\right) \\
& +\sum_{i}^{S} \sum_{j}^{N} \sum_{k \neq j}^{N} \sum_{l}^{B} \sum_{m}^{B} y_{i j k}^{l m} C_{i j k}^{l m}\left(t d_{i k}^{m}-t a_{i j}^{l}\right)
\end{aligned}
$$

Subject to:

$$
\begin{gathered}
C_{i j}^{l} \leq C_{\max }, \forall i, j, l \\
D_{i j}^{l}=C_{i-1 j}^{l}\left(1-\varsigma_{i j}^{l}\right)+\mu_{i j}^{l}\left(t d_{i j}^{l}-t d_{i j}^{l-1}\right)+n r t_{i j}^{l-1} \\
\forall i, j, l \geq 1 \\
n r t_{i j}^{l}=\max \left\{0, D_{i j}^{l}-C_{\max }\right\}, \forall i, j, l \\
t a_{i j}^{l}=t d_{i j}^{l-1}+h_{i j} \\
t d_{i j}^{l}=t a_{i j}^{l}+\tau_{a} n d e s_{i j}^{l}+\tau_{b}\left(\mu_{i j}^{l} h_{i j}-n r t_{i j}^{l}\right)+\alpha_{i j}^{l}(12) \\
t a_{i j}^{l}-t a_{i j}^{l-1} \leq h_{i j}, \forall i, j, l \geq 1 \\
y_{i j k}^{l m}\left(t d_{i k}^{m}-t a_{i j}^{l}\right) \leq T, \forall i, j, k, l, m \\
\xi_{i j}^{l}=\{0,1\}, \forall i, j, l \\
y_{i j k}^{l m}=\{0,1\}, \forall i, j, k, l, m \\
0 \leq \theta_{i l}^{l}<1 \\
t d_{i j}^{l}, t a_{i j}^{l}, \varsigma_{i j}^{l}, n r t_{i j}^{l} \geq 0, \forall i, j, l
\end{gathered}
$$

Constraint (8) restricts the number of passengers onboard when the bus departs the station. The demand for bus $l$ at station $i$ is calculated by constraint (9). Constraints (3) (10) show that the value $n r t_{i j}^{l}$ depends on the demand for bus $l$ at station $i$, on the number of available seats on the bus $l$ after alighting, and on the strategy is applied.

Arrival time and departure time are calculated (11), (12), based on the duration, between bus $l$ and $l-1$, the duration for passengers boarding, alighting and bus clearance time, with an initial condition $t d_{i j}^{0}=0$. Constraint (13) states that the headway should not be larger than a stipulated maximum headway $h_{i j}$. Constraint (14) restricts the transfer time for any transfer. Constraint (15) defines the decision variable for using skipping station or not. Constraint (16) assures that a transfer from bus $l$ of line $j$ to bus $m$ of line $k$ at station $i$ is possible or not possible. Constraint (17) shows the fraction of passenger inbus on skipping stations.
In the above formulation, the variables $y_{i j k}^{l m}, \xi_{i j}^{l}$ are binary, taking 1 or 0 , this make the search space discrete. Otherwise the objective function and the constraint (10) makes the formulation(7) becomes nonlinear and difficult to solve with classical methods.

\section{SIMULATED ANNEALING ALGORITHMS(SA)}

\subsection{Introduction}

As one of the widely used heuristic approaches (including genetic algorithm and local search) to solve combinatorial problems, simulated annealing (SA) can produce a good though not necessarily global optimal solution within a reasonable computing time. Simulated annealing is a Monte Carlo simulation based search algorithm. The term "simulated annealing" is derived from a process of heating and then cooling a substance slowly to finally arrive at the solid state. In this simulation, a minimum of the cost function corresponds to this ground state of the substance. The whole search algorithm simply mimics the physical process as below. In the early stages of the execution, the temperature is high, which results in a higher probability for jumping to occur more frequently. In this case, the frequent jumping, which occurs as a way of avoiding local minima, may produce a higher probability of a poor solution. In another way, simulated annealing selects the next point randomly. If a lower cost solution is found, it is selected. If a higher cost solution is found, it has a nonzero selection probability. The function that governs the behaviour of the acceptance probability is called the cooling schedule. As the execution time elapses, the temperature decreases and the cooling schedule reduces the frequency of jumping.

The simulation process terminates after a number of successive executions with no improvements, and returns the best solution found. The following code provides an illustration of the SA algorithm in pseudo-code (Eglese, et al., 1990):

Select an initial state $i \in S$

Select an initial temperature $T>0$

Set temperature change counter $t=0$

Repeat

Set repetition counter $n=0$ (number of iterations to be performed at each temperature)

Repeat

Generate state $j$, a neighbour of $i$

Calculate $\delta=f(j)-f(i)$.

If $\delta=0$ then $i=j$

Else if random $(0,1)<\exp (-\delta / T)$ then $i=j$

$n+=1$

Until $n=N(t)$

$t+=1$

$T=T(t)$

Until stopping criteria is true. 
As can be seen, the annealing schedule consists of:

- the initial value of $T$

- a cooling function

- the number of iterations $N(t)$ to be performed at each temperature

- a stopping criteria to terminate the algorithm

In SA, the algorithm attempts to avoid entrapment in a local optimum by sometimes accepting a neighbourhood movement, which increases the value of the objective function. The acceptance or rejection of an uphill move is determined by a sequence of random numbers, but with a controlled probability. The probability of accepting a move, which causes an increase $\delta$ in $f$ is called the acceptance function and is normally set to $\exp (-\delta / T)$ where $T$ is a control parameter, which is analogous to temperate in a physical annealing.

In this paper, for the model describe in section 3, the cost function is defined as the total passenger waiting time and a neighbour is generated by adding or reducing the interval of time received at each station by skipping control decision. The algorithm was coded in Visual C\# 2005 and implemented on a Pentium $\mathrm{M}$ with $1.7 \mathrm{GHz}$ CPU.

\section{SIMULATION RESULTS}

\subsection{Illustrative Example}

Consider a branch of bus network at Grenoble, composed of $N=8$ lines. The line 1 is crossed in 7 stations $S 11, S 14, S 15, S 18, S 22, S 24, S 26$ with others lines. Line 1 contains 30 stations, with planned headway $h=7$ minutes, and reserved by three buses. Let us study a disturbance that affects the second bus $B_{1}^{2}$ of the line 1 . This disturbance is detected at $8 \mathrm{~h} 31$ and bus $B_{1}^{2}$ arrives at all downstream stations 5 minutes late. Therefore, the transit operation with others lines would not occur at transfers stations.

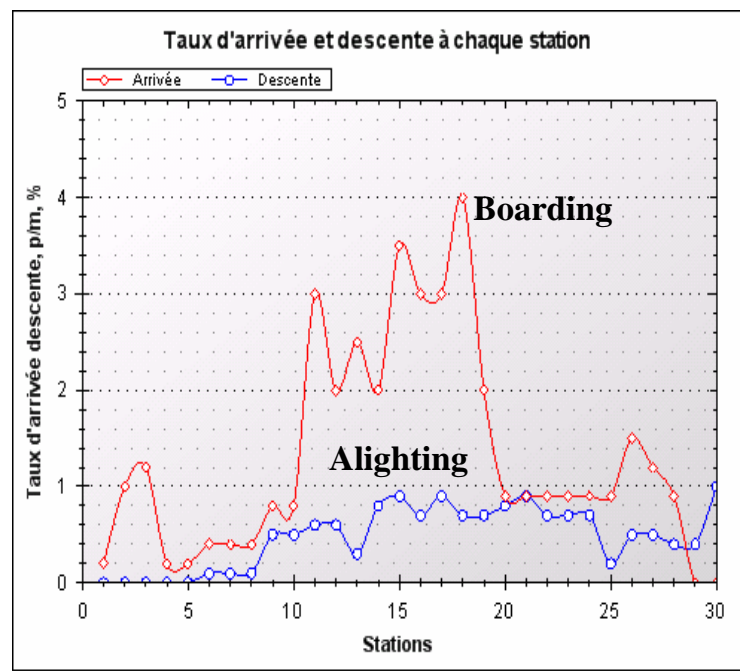

Fig. 2. Passenger demand
Theoretical timetable of line 1 and timetable for transfer are given in Table 1 and Table 2, the lights greys areas are stations (stations 11, 15, 18, 24), where passengers alight the bus of line 1 and board another bus of others lines, the darks greys are stations (stations 14, 22, 26), where passengers alight from another buses of others lines and wait for boarding buses of line 1. After the disturbance, the disturbed timetable is shown in Table 3. The base demand profile of boarding and alighting for the line 1 is presented in Fig. 2.

Following parameters are chosen for rescheduling problem:

- Boarding time for each passenger $=0.05$ minute

- Bus clearance time $=0.2$ minute

- Bus capacity $C_{\max }=60$

- Maximum transfer time at each station $T=3$ minutes

\subsection{Results}

The application of the solution given by our SA is illustrated in Table 4. In this solution, decision which will be applied to skip stations $[S 5, S 8]$, with the respect of constraints. We notice that, instead of waiting for a next bus $B_{1}^{3}$ for boarding in skipping segment $[S 5, S 8]$, the objective function is optimized. The detail of objective function value is illustrated in Table 5. The objective function, which computes the total waiting time for all passengers non-transferring and transferring at any stations, has a value of 3604.9 minutes in case of disturbances. It indicates that, if the regulator does nothing, the expected total waiting time for all passengers will increase by 1418 minutes (3604.9-2186.9=1418). Applying the proposed model to the problem, the solution found after $1 \mathrm{~s}$ computational time is to skip bus $B_{1}^{2}$ at skipping segment stations $[S 5, S 8]$. By doing that, the total waiting time for all passengers non-transferring and transferring at any stations, has a value of 2699 minutes. Otherwise, the total time waiting time for passenger non-transferring has been reduced by $18.8 \%$ ((2871-2329.9)/2871), and the total waiting time for transferring passengers has been reduced by $49.7 \%$ ((733.9-369.1)/733.9)). The total waiting time at each station is shown in Fig. 3.

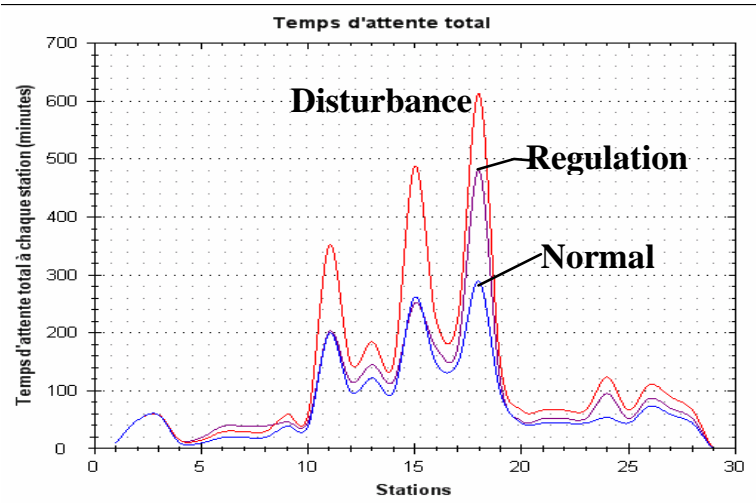

Fig. 3. Waiting time at each station 
Table 5 Computation results for the example

\begin{tabular}{lcr} 
& Waiting time & Transfer time \\
\hline Theoretical & $(1)$ & $(2)$ \\
Line 1 & 1940.4 & 246.5 \\
Disturbed & (1) 2871 & (2) 733.9 \\
Line 1 & (1) 2329.9 & (2) 369.1 \\
Skipping & 2329.9 & \\
Line 1 &
\end{tabular}

\section{CONCLUSION}

This paper presented a modified mathematical model for real-time stop skipping in the urban transportation networks. The developed model is flexible in adapting to buses capacities conditions when a given bus departs a station along a given line when the disturbances happen. A heuristic algorithms based on SA is presented to solve this model. The efficiency of the algorithm was tested using a numerical example. The results indicate that applying real-time stop-skipping strategy can reduce passengers' waiting time, improve transit service quality and operating efficiency in case of disturbances. This strategy is most effective on the line with short headways and high passenger demand. As perspective of this research work need in the comparison and the combination with other methods, develop other control strategies (Deadheading, adding a reserve bus...), the presentation of other mode of transport (Tramway, Metro...).

\section{REFERENCES}

Borne, Besma Fayech, Slim Hammadi, Salah Maouche (2003). Decision support system for urban transportation networks, IEEE Transactions on Systems, Man and Cybernetics, Part C, Vol. 33, No. 1, pp.67-77.

Eberlein, X. J., N. H. M. Wilson, C.Barnhart, and D. Bernstein (1998). The Real-Time Deadheading Problem in Transit Operations Control, Transportation Research B, Vol. 32, No. 2, pp.77100.

Eglese, R.W (1990). Simulated annealing: A Tool for Operational Research, European Journal of Operational Research, Vol. 46, pp.271-281.

Fu.L and Lui.Q (2003). A real time optimization model for dynamic scheduling of transit operation, 82nd Annual Meeting of the Transportation Research Board, Washington DC.

Li, Y., J.-M. Rousseau, and M. Gendreau (1991). Real-Time scheduling on a transit bus route: A 0-1 stochastic programming model, 33rd Annual Meeting of the Transportation Research Forum, pp.157-166.

Table 1 Theoretical timetable of line 1

\begin{tabular}{ccccccccccccccccccccccccccccccccccccc}
$\mathrm{S}$ & 1 & 2 & 3 & 4 & 5 & 6 & 7 & 8 & 9 & 10 & 11 & 12 & 13 & 14 & 15 & 16 & 17 & 18 & 19 & 20 & 21 & 22 & 23 & 24 & 25 & 26 & 27 & 28 & 29 & 30 \\
\hline $\mathrm{B}$ & 1 & 2 & $\mathrm{H}$ & $8 \mathrm{H}$ & $8 \mathrm{H}$ & $8 \mathrm{H}$ & $8 \mathrm{H}$ & $8 \mathrm{H}$ & $8 \mathrm{H}$ & $8 \mathrm{H}$ & $8 \mathrm{H}$ & $8 \mathrm{H}$ & $8 \mathrm{H}$ & $8 \mathrm{H}$ & $8 \mathrm{H}$ & $8 \mathrm{H}$ & $8 \mathrm{H}$ & $8 \mathrm{H}$ & $8 \mathrm{H}$ & $8 \mathrm{H}$ & $8 \mathrm{H}$ & $8 \mathrm{H}$ & $8 \mathrm{H}$ & $8 \mathrm{H}$ & $8 \mathrm{H}$ & $8 \mathrm{H}$ & $9 \mathrm{H}$ & $9 \mathrm{H}$ & $9 \mathrm{H}$ & $9 \mathrm{H}$ & $9 \mathrm{H}$ & $9 \mathrm{H}$ \\
\hline & 21 & 22 & 24 & 25 & 26 & 27 & 28 & 30 & 31 & 33 & 35 & 36 & 38 & 39 & 40 & 42 & 44 & 45 & 46 & 49 & 52 & 55 & 56 & 58 & 01 & 03 & 05 & 06 & 07 & 08 \\
& $8 \mathrm{H}$ & $8 \mathrm{H}$ & $8 \mathrm{H}$ & $8 \mathrm{H}$ & $8 \mathrm{H}$ & $8 \mathrm{H}$ & $8 \mathrm{H}$ & $8 \mathrm{H}$ & $8 \mathrm{H}$ & $8 \mathrm{H}$ & $8 \mathrm{H}$ & $8 \mathrm{H}$ & $8 \mathrm{H}$ & $8 \mathrm{H}$ & $8 \mathrm{H}$ & $8 \mathrm{H}$ & $8 \mathrm{H}$ & $8 \mathrm{H}$ & $8 \mathrm{H}$ & $8 \mathrm{H}$ & $8 \mathrm{H}$ & $9 \mathrm{H}$ & $9 \mathrm{H}$ & $9 \mathrm{H}$ & $9 \mathrm{H}$ & $9 \mathrm{H}$ & $9 \mathrm{H}$ & $9 \mathrm{H}$ & $9 \mathrm{H}$ & $9 \mathrm{H}$ \\
2 & 28 & 29 & 31 & 32 & 33 & 34 & 35 & 37 & 38 & 40 & 42 & 43 & 45 & 46 & 47 & 49 & 51 & 52 & 53 & 56 & 59 & 02 & 03 & 05 & 08 & 10 & 12 & 13 & 14 & 15 \\
& $8 \mathrm{H}$ & $8 \mathrm{H}$ & $8 \mathrm{H}$ & $8 \mathrm{H}$ & $8 \mathrm{H}$ & $8 \mathrm{H}$ & $8 \mathrm{H}$ & $8 \mathrm{H}$ & $8 \mathrm{H}$ & $8 \mathrm{H}$ & $8 \mathrm{H}$ & $8 \mathrm{H}$ & $8 \mathrm{H}$ & $8 \mathrm{H}$ & $8 \mathrm{H}$ & $8 \mathrm{H}$ & $8 \mathrm{H}$ & $8 \mathrm{H}$ & $9 \mathrm{H}$ & $9 \mathrm{H}$ & $9 \mathrm{H}$ & $9 \mathrm{H}$ & $9 \mathrm{H}$ & $9 \mathrm{H}$ & $9 \mathrm{H}$ & $9 \mathrm{H}$ & $9 \mathrm{H}$ & $9 \mathrm{H}$ & $9 \mathrm{H}$ & $9 \mathrm{H}$ \\
3 & 35 & 36 & 38 & 39 & 40 & 41 & 42 & 44 & 45 & 47 & 49 & 50 & 52 & 53 & 54 & 56 & 58 & 59 & & 03 & 06 & 09 & 10 & 12 & 15 & 17 & 19 & 20 & 21 & 22 \\
\hline
\end{tabular}

Table 2 Timetable of others lines at transfer stations with line 1

\begin{tabular}{ccccccccc}
$\mathrm{S} / \mathrm{B}$ & 11 & 14 & 15 & 18 & 22 & 24 & 26 \\
\hline 1 & $8 \mathrm{H} 37$ & $8 \mathrm{H} 38$ & $8 \mathrm{H} 43$ & $8 \mathrm{H} 47$ & $8 \mathrm{H} 53$ & $9 \mathrm{H} 01$ & $9 \mathrm{H} 01$ \\
2 & $8 \mathrm{H} 45$ & $8 \mathrm{H} 45$ & $8 \mathrm{H} 50$ & $8 \mathrm{H} 55$ & $9 \mathrm{H}$ & $9 \mathrm{H} 08$ & $9 \mathrm{H} 08$ \\
3 & $8 \mathrm{H} 53$ & $8 \mathrm{H} 53$ & $8 \mathrm{H} 58$ & $9 \mathrm{H} 04$ & $9 \mathrm{H} 08$ & $9 \mathrm{H} 15$ & $9 \mathrm{H} 16$ \\
\hline
\end{tabular}

Table 3 Disturbed timetable of line 1

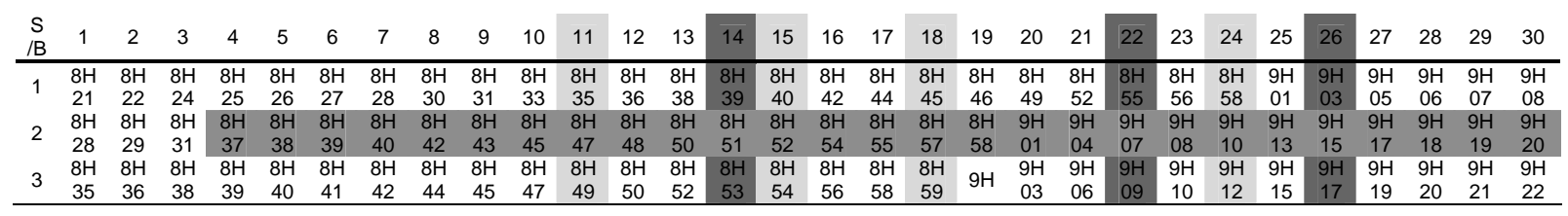

Table 4 Solution timetable of line 1

\begin{tabular}{cccccccccccccccccccccccccccccccc}
$\mathrm{S}$ & 1 & 2 & 3 & 4 & 5 & 6 & 7 & 8 & 9 & 10 & 11 & 12 & 13 & 14 & 15 & 16 & 17 & 18 & 19 & 20 & 21 & 22 & 23 & 24 & 25 & 26 & 27 & 28 & 29 & 30 \\
\hline \multirow{2}{*}{1} & $8 \mathrm{H}$ & $8 \mathrm{H}$ & $8 \mathrm{H}$ & $8 \mathrm{H}$ & $8 \mathrm{H}$ & $8 \mathrm{H}$ & $8 \mathrm{H}$ & $8 \mathrm{H}$ & $8 \mathrm{H}$ & $8 \mathrm{H}$ & $8 \mathrm{H}$ & $8 \mathrm{H}$ & $8 \mathrm{H}$ & $8 \mathrm{H}$ & $8 \mathrm{H}$ & $8 \mathrm{H}$ & $8 \mathrm{H}$ & $8 \mathrm{H}$ & $8 \mathrm{H}$ & $8 \mathrm{H}$ & $8 \mathrm{H}$ & $8 \mathrm{H}$ & $8 \mathrm{H}$ & $8 \mathrm{H}$ & $9 \mathrm{H}$ & $9 \mathrm{H}$ & $9 \mathrm{H}$ & $9 \mathrm{H}$ & $9 \mathrm{H}$ & $9 \mathrm{H}$ \\
& 21 & 22 & 24 & 25 & 26 & 27 & 28 & 30 & 31 & 33 & 35 & 36 & 38 & 39 & 40 & 42 & 44 & 45 & 46 & 49 & 52 & 55 & 56 & 58 & 01 & 03 & 05 & 06 & 07 & 08 \\
& $8 \mathrm{H}$ & $8 \mathrm{H}$ & $8 \mathrm{H}$ & $8 \mathrm{H}$ & $8 \mathrm{H}$ & $8 \mathrm{H}$ & $8 \mathrm{H}$ & $8 \mathrm{H}$ & $8 \mathrm{H}$ & $8 \mathrm{H}$ & $8 \mathrm{H}$ & $8 \mathrm{H}$ & $8 \mathrm{H}$ & $8 \mathrm{H}$ & $8 \mathrm{H}$ & $8 \mathrm{H}$ & $8 \mathrm{H}$ & $8 \mathrm{H}$ & $8 \mathrm{H}$ & $8 \mathrm{H}$ & $9 \mathrm{H}$ & $9 \mathrm{H}$ & $9 \mathrm{H}$ & $9 \mathrm{H}$ & $9 \mathrm{H}$ & $9 \mathrm{H}$ & $9 \mathrm{H}$ & $9 \mathrm{H}$ & $9 \mathrm{H}$ & $9 \mathrm{H}$ \\
2 & 28 & 29 & 31 & 37 & 38 & 39 & 40 & 42 & 41 & 43 & 45 & 47 & 49 & 50 & 51 & 53 & 54 & 55 & 57 & 59 & 00 & 03 & 06 & 08 & 11 & 14 & 16 & 17 & 18 & 19 \\
& $8 \mathrm{H}$ & $8 \mathrm{H}$ & $8 \mathrm{H}$ & $8 \mathrm{H}$ & $8 \mathrm{H}$ & $8 \mathrm{H}$ & $8 \mathrm{H}$ & $8 \mathrm{H}$ & $8 \mathrm{H}$ & $8 \mathrm{H}$ & $8 \mathrm{H}$ & $8 \mathrm{H}$ & $8 \mathrm{H}$ & $8 \mathrm{H}$ & $8 \mathrm{H}$ & $8 \mathrm{H}$ & $8 \mathrm{H}$ & $8 \mathrm{H}$ & $9 \mathrm{H}$ & $9 \mathrm{H}$ & $9 \mathrm{H}$ & $9 \mathrm{H}$ & $9 \mathrm{H}$ & $9 \mathrm{H}$ & $9 \mathrm{H}$ & $9 \mathrm{H}$ & $9 \mathrm{H}$ & $9 \mathrm{H}$ & $9 \mathrm{H}$ & $9 \mathrm{H}$ \\
3 & 35 & 36 & 38 & 39 & 40 & 41 & 42 & 44 & 45 & 47 & 49 & 50 & 52 & 53 & 54 & 56 & 58 & 59 & $\mathrm{H}$ & 03 & 06 & 09 & 10 & 12 & 15 & 17 & 19 & 20 & 21 & 22 \\
\hline
\end{tabular}

